\title{
AVALIAÇÃO DA GESTÃO DE RESÍDUOS SÓLIDOS URBANOS NO MUNICÍPIO DE ORLEANS - SC
}

\author{
EVALUATION OF SOLID WASTE MANAGEMENT IN THE \\ COUNTY OF ORLEANS - SC
}

\section{Mário Ricardo Guadagnin \\ Professor da Universidade do \\ Extremo Sul Catarinense - \\ UNESC. E-mail: mrg@unesc.net}

Maria Victoria Prestes

Luchese

Acadêmica do curso de Engenharia Ambiental e Sanitária na Universidade do Extremo Sul Catarinense (UNESC) - Criciúma (SC), Brasil. E-mail: mvluchese@gmail.com

\section{RESUMO}

O artigo apresenta um estudo de caso realizado para avaliar o nível de sustentabilidade da gestão de resíduos sólidos urbanos no município de Orleans - SC. O método de avaliação foi baseado na revisão bibliográfica acadêmica sobre indicadores de sustentabilidade e na coleta de dados em órgãos públicos. A formulação e adequação de indicadores de sustentabilidade preestabelecidos pelos estudos realizados por Santiago e Dias (2012), Polaz e Teixeira (2009) e Fechine e Moraes (2014) foram aplicados à realidade da gestão do município de Orleans - SC. A matriz de indicadores utilizada é composta por cinco dimensões de sustentabilidade (política/institucional, operacional, econômica, ambiental/ecológica e social/cultural), 44 indicadores e 132 descritores. $O$ intervalo de sustentabilidade obtido após o cálculo das pontuações alcançadas em cada indicador estabeleceu um nível médio de sustentabilidade da gestão de RSU no município. A análise qualitativa das dimensões salienta alguns aspectos negativos que impedem que o serviço prestado seja considerado sustentável. Os principais fatores são a não sistematização de dados referentes aos processos de gerenciamento, problemas na estruturação da equipe administrativa e insuficiência de informações necessárias para indicar custos. Os resultados obtidos apontam a eficácia do método utilizado neste estudo e ressaltam a importância da avaliação e monitoramento dos serviços prestados, que podem contribuir no planejamento e gerenciamento, além de tornar as características da gestão mais transparentes para a sociedade.

Palavras-chaves: Gerenciamento. Indicadores de sustentabilidade. Gestão ambiental.

\begin{abstract}
This article presents a case study developed to evaluate the sustainability level of the solid management in the county of Orleans, SC. The valuation method was based on the literature review about sustainability indicators and data collection by interviewing municipal managers. The formulation and appropriateness of sustainability indicators predetermined by the studies performed for Santiago e Dias (2012), Polaz e Teixeira (2009) e Fechine e Moraes (2014) according to the management reality of the county of Orleans, SC. The Indicators Matrix applied has 5 dimensions of sustainability (political/institutional, operational, economic, environmental/ecological and social/cultural) 44 indicators and 132 descriptors. The sustainability interval obtained after the calculation of the scores reached in each indicator has settled an average level of sustainability of the solid waste management in the county. The qualitative analysis emphasizes some negative aspects that prevent the sustainability of the service. The main factors are non data systematization about the processes
\end{abstract}


management, problems with structuring the administration staff and insufficient relevant details to calculate costs. The results proved the effectiveness of this study method and how the evaluation and monitoring of the service can contribute in the planning and management, in addition to make transparent the characteristics for society.

Keywords: Management. Sustainability indicators. Environmental management. 


\section{INTRODUÇÃO}

A Lei 12.305, de 2 de agosto de 2010, que institui a Política Nacional de Resíduos Sólidos, tramitou por 21 anos nas esferas legislativas brasileiras, até entrarem em vigor as normas gerais para a gestão dos resíduos sólidos. A complexidade da gestão de resíduos cria um desafio em harmonizar os diferentes segmentos da organização do Poder Público (União, Estados, Distrito Federal e Municípios), a fim de não ultrapassar os limites nem ferir a autonomia dos poderes.

A responsabilidade da gestão de resíduos recentemente se concentrava no poder público, excluindo dessa obrigação o setor empresarial e a sociedade civil. O advento da nova política traz conceitos inéditos como a responsabilidade compartilhada pelo ciclo de vida do produto, onde engloba, no Art. $3^{\circ}$, parágrafo XVII:

\footnotetext{
Conjunto de atribuições individualizadas e encadeadas dos fabricantes, importadores, distribuidores e comerciantes, dos consumidores e dos titulares dos serviços públicos de limpeza urbana e de manejo dos resíduos sólidos, para minimizar o volume de resíduos sólidos e rejeitos gerados, bem como para reduzir os impactos causados à saúde humana e à qualidade ambiental decorrentes do ciclo de vida dos produtos, nos termos desta Lei (BRASIL, 2010).
}

A Gestão Integrada dos Resíduos Sólidos (GIRS) toma uma nova concepção, ainda desconhecida por muitos gestores, que leva ao gerenciamento errôneo dos resíduos, tornando essa atividade custosa e ineficiente (BELLINGIERI, 2012).

Os gestores municipais, muitas vezes, tomam decisões baseadas em dados imprecisos, e não há um sistema efetivo que avalie essas ações. Por exemplo, muitos acreditam que poderiam avaliar o gerenciamento do lixo urbano, analisando somente as condições da disposição final dos resíduos sólidos (DANTAS, 2008).

Diante da complexidade da GIRS, diversos indicadores devem ser avaliados, a fim de verificar a adequação e os ajustes necessários do gerenciamento de resíduos, conforme a legislação vigente.

A elaboração de indicadores para avaliar a sustentabilidade ambiental, social, econômico-financeira e sanitária dos programas pode ser um instrumento relevante para monitorar os programas, propor metas e alternativas de gestão e ampliar seu alcance e seu fortalecimento (BESEN; RIBEIRO, 2008). 
Milanez (2002) ressalta que a definição e escolha dos indicadores, todavia, não é uma tarefa trivial. Devido à complexidade dos assuntos que abordam, normalmente é necessária uma lista ampla e abrangente de indicadores que tenha relação causal com toda a variedade de atividades da sociedade. $\mathrm{O}$ autor ainda lembra que, de forma geral, os indicadores tentam integrar as diferentes dimensões da sustentabilidade, tornando possível, através de sua interpretação, a análise da real qualidade de vida e das perspectivas da comunidade.

Antes da implementação da Lei 12.305/2010, muitos estudos sobre métodos de avaliação do grau de sustentabilidade já vinham sido desenvolvidos (MILANEZ, 2002; DANTAS, 2008; BESEN; RIBEIRO, 2009). A utilização de indicadores de sustentabilidade de gestão e gerenciamento de resíduos sólidos aplicados aos municípios possibilita a avaliação do desempenho operacional dos serviços públicos de manejo de resíduos e limpeza urbana. A execução desse trabalho é pioneira na região sul de Santa Catarina, e a continuação em anos seriados possibilita a verificação do atendimento às metas estabelecidas nos Planos Regionais e/ou Planos Municipais de Gestão Integrada de Resíduos Sólidos conforme preconiza a Política Nacional de Resíduos Sólidos.

Por esse motivo, foi desenvolvido o presente estudo, com o objetivo de aplicar os métodos utilizados por pesquisadores da área, citados no decorrer deste artigo, para avaliar a sustentabilidade da gestão de resíduos sólidos em Orleans - SC, um dos municípios pertencentes à Associação dos Municípios da Região Carbonífera (AMREC) de Santa Catarina.

\section{O MUNICÍPIO EM ESTUDO E A GESTÃO DE RESÍDUOS SÓLIDOS}

O município de Orleans localiza-se no sul do estado de Santa Catarina. Pertence à Microrregião da Região Carbonífera e da AMREC - Associação dos Municípios da Região Carbonífera, como mostra a Figura 1. Sua economia está baseada na indústria, comércio e agricultura. Possui $550 \mathrm{~km}^{2}$ de área. Segundo a estimativa realizada pelo IBGE, a população total de Orleans no ano de 2016 seria de 22.587 habitantes.

O município faz parte do Consórcio Intermunicipal de Resíduos Sólidos Urbanos da Região Sul (CIRSURES), juntamente com os municípios de Cocal do Sul, Lauro Muller, Morro da Fumaça, Siderópolis, Treviso e Urussanga. O Plano Intermunicipal de Gestão Integrada de Resíduos Sólidos (PIGIRS) foi elaborado pelo Instituto de Pesquisas Ambientais 
e Tecnológicas (IPAT) da Universidade do Extremo Sul Catarinense (UNESC). O plano engloba todos os requisitos necessários para o desenvolvimento dos processos de gerenciamento de resíduos sólidos nos municípios.

Figura 1 - Localização do Município de Orleans - SC

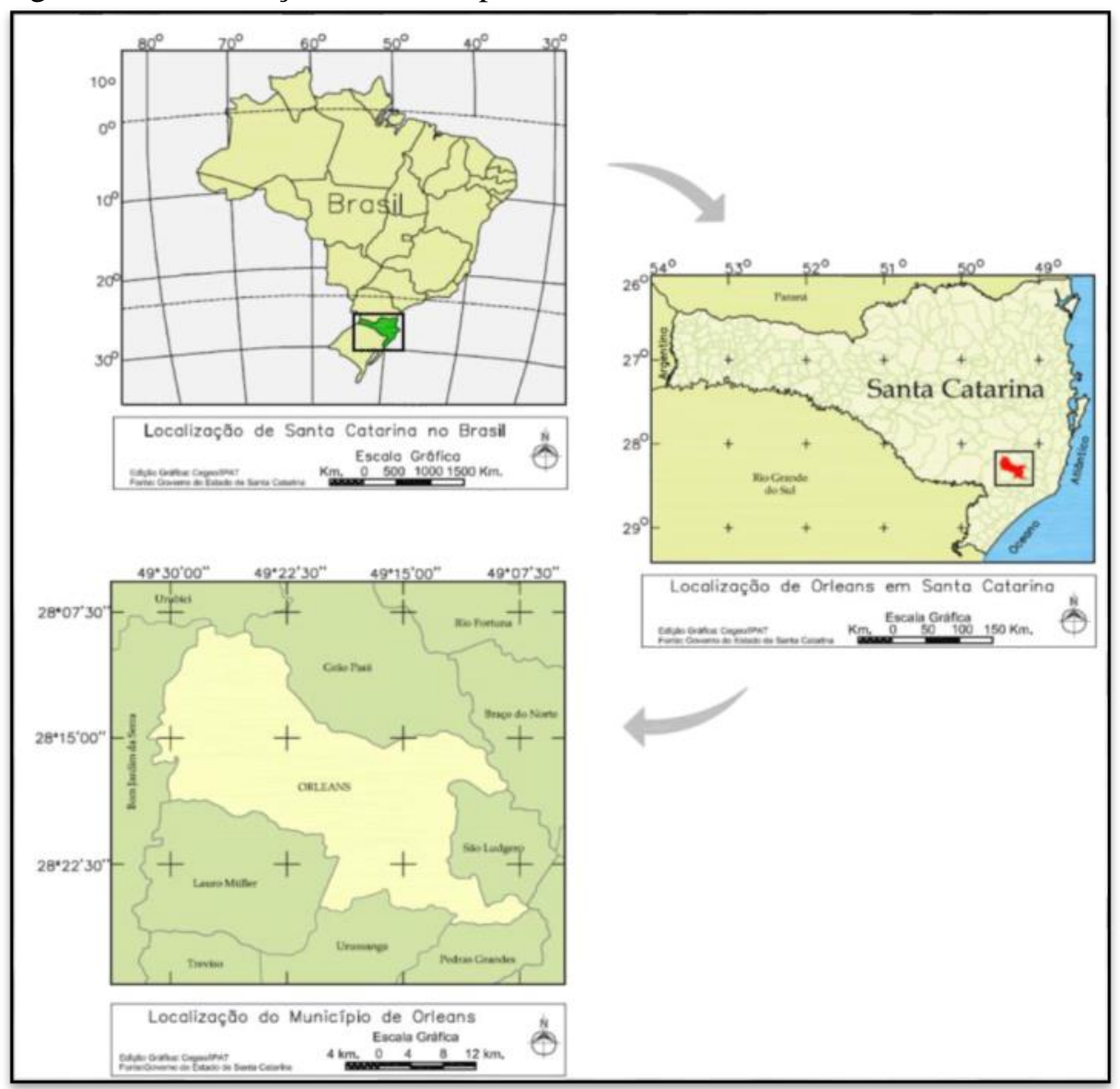

Fonte: IPAT, 2012.

O CIRSURES (CNPJ: 04.570.787/0001-17) foi criado em 2001 e possui aterro sanitário localizado no Bairro Rio Carvão, município de Urussanga. O local recebe em média 1.000 toneladas/mês de resíduos sólidos urbanos, gerados pelos municípios consorciados. A vida útil é de 14 anos, com prazo de encerramento previsto para o ano de 2017 e possui capacidade total projetada para $320.833 \mathrm{~m}^{3}$ de resíduos sólidos. O aterro possui Licença Ambiental de Operação Fatma - n. 9478/2013 e Alvará Sanitário da Vigilância Sanitária n. 0294/2015. A coleta convencional é realizada pela Prefeitura Municipal de Orleans, e o consórcio é responsável pelo tratamento e destinação final dos resíduos.

A coleta seletiva foi implantada no município de Orleans em 2015, e é realizada pelo CIRSURES junto à Cooperativa de Reciclagem do Rio América - Cooperamérica. Trata-se de uma cooperativa de catadores criada em 2007 e localizada em terreno contíguo anexo ao 
aterro sanitário do CIRSURES. É responsável pela execução da triagem e comercialização dos materiais recicláveis coletados pela equipe de coleta seletiva intermunicipal do CIRSURES.

Os dados referentes à abrangência, geração per capta e custos das coletas, tanto a convencional quanto a seletiva, estarão descritos ao longo da metodologia e resultados deste artigo.

\section{METODOLOGIA}

Iniciou-se a pesquisa descritiva com traços exploratórios de concepção pragmática orientada para prática no mundo real e documental com o levantamento bibliográfico de artigos científicos, dissertações, teses e livros sobre gestão de resíduos sólidos e métodos com indicadores de desempenho e sustentabilidade utilizados para avaliação.

Após a consulta dos trabalhos desenvolvidos, o estudo da Lei 12.305/2010 e a leitura de planos de gestão de RSU, utilizou-se metodologia mista, com a análise quantitativa e qualitativa dos dados, precedendo à realização da fase qualitativa de análise de PMGIRS. Na etapa de pesquisa bibliográfica e revisão de literatura, foram selecionados os estudos que serviram como base para o desenvolvimento de uma matriz de indicadores adequada à realidade dos municípios integrantes da AMREC e que possibilitam uma metodologia de avaliação clara e objetiva. A pesquisa que utiliza metodologia mista com dados qualitativos e quantitativos que podem ser unidos por um grande banco de informações ou os resultados podem ser colocados lado a lado para reforçarem-se mutuamente, na suposição de que a coleta de diversos dados possibilite um entendimento melhor do problema de pesquisa. Os procedimentos de métodos mistos sequenciais são aqueles em que o pesquisador procura elaborar ou expandir os achados de um método com outro método (CRESWELL, 2010).

Durante a leitura das pesquisas, observou-se um padrão de indicadores utilizados para a composição de matrizes de avaliação e alguns pontos que impossibilitam uma aplicação geral. Por esse motivo, fez-se necessária a integração de dados dos principais estudos utilizados, esses citados no Quadro 1.

Quadro 1 - Principais estudos utilizados

\begin{tabular}{l|l} 
Fonte & Estudo realizado
\end{tabular}


SANTIAGO, Leila Santos; DIAS, Sandra Maria Furiam (2012)

\section{POLAZ, Carla Natacha}

Marcolino; TEIXEIRA,

Bernardo Arantes do Nascimento (2009)

FECHINE, Roberta; MORAES, Luiz Roberto Santos (2014)
Matriz de Indicadores de sustentabilidade para a gestão de resíduos sólidos urbanos

Fonte: Pesquisa bibliográfica, 2017.

Indicadores de sustentabilidade para a gestão municipal de resíduos sólidos urbanos: um estudo para São Carlos (SP)

A integração das metodologias e de indicadores propostos pelos autores citados resultou em uma matriz de indicadores que é compatível com as características do município em estudo. Seguindo os modelos propostos, a matriz é composta por cinco dimensões de sustentabilidade e um total de 44 indicadores, com três descritores para cada indicador. A estrutura segue a mesma divisão proposta por Santiago e Dias (2012), com a especificação da dimensão, indicador, descritor, nota e peso. As dimensões de sustentabilidade utilizadas foram baseadas nos estudos, mas com alterações na estrutura e adaptadas para melhor se adequar às características da cidade avaliada, como apresenta o Quadro 2.

Quadro 2 - Descrição das dimensões de sustentabilidade

\begin{tabular}{|c|c|c|}
\hline Dimensões & Descrição & Referências \\
\hline $\begin{array}{c}\text { Política/ } \\
\text { Institucional }\end{array}$ & $\begin{array}{l}\text { Relacionada com a adoção de atos regulamentários/normativos } \\
\text { em políticas de gestão de RS, normas e atos em conformidade } \\
\text { com as orientações nacionais e em atenção às demandas locais de } \\
\text { gerenciamento de resíduos e democratização da informação. }\end{array}$ & $\begin{array}{l}\text { POLAZ e TEIXEIRA } \\
\text { (2009), SANTIAGO e } \\
\text { DIAS (2012), FECHINE } \\
\text { e MORAES (2014) }\end{array}$ \\
\hline $\begin{array}{l}\text { Operacional } \\
1 \\
\text { Operacional } \\
2 \\
\end{array}$ & $\begin{array}{l}\text { Informações referentes a processos operacionais utilizados na } \\
\text { coleta convencional e coleta seletiva: qualidade estrutural, } \\
\text { geração, tecnologia e trabalhadores envolvidos nos processos. }\end{array}$ & $\begin{array}{l}\text { SANTIAGO e DIAS } \\
\text { (2012), FECHINE e } \\
\text { MORAES (2014) }\end{array}$ \\
\hline Econômica & $\begin{array}{l}\text { Está relacionada com a fonte, a destinação e a administração } \\
\text { correta dos recursos financeiros disponibilizados para a } \\
\text { manutenção da GRSU. }\end{array}$ & $\begin{array}{l}\text { POLAZ e TEIXEIRA } \\
\text { (2009), SANTIAGO e } \\
\text { DIAS (2012), FECHINE } \\
\text { e MORAES (2014) } \\
\end{array}$ \\
\hline $\begin{array}{l}\text { Ambiental/ } \\
\text { Ecológica }\end{array}$ & $\begin{array}{l}\text { Consiste na limitação do uso dos recursos naturais não } \\
\text { renováveis, na preservação da capacidade de autodepuração dos } \\
\text { ecossistemas e avaliação de impactos ambientas. }\end{array}$ & $\begin{array}{l}\text { POLAZ e TEIXEIRA } \\
\text { (2009), SANTIAGO e } \\
\text { DIAS (2012) }\end{array}$ \\
\hline $\begin{array}{c}\text { Social } \\
\text { Cultural }\end{array}$ & $\begin{array}{l}\text { Está relacionada à cooperação e participação social, garantia de } \\
\text { condições adequadas de trabalho, estímulo à cidadania. } \\
\text { Contextualização e valorização local, programas de educação } \\
\text { ambiental, mobilização social e incentivo à cultura. }\end{array}$ & $\begin{array}{l}\text { SANTIAGO e DIAS } \\
\text { (2012), FECHNE e } \\
\text { MORAES (2014) }\end{array}$ \\
\hline
\end{tabular}

Fonte: Adaptado da pesquisa bibliográfica, 2017 
A dimensão operacional possui uma subdivisão para possibilitar a avaliação da gestão da coleta convencional e da coleta seletiva separadamente. Essa estrutura facilita o processo de avaliação e mostra com clareza os resultados obtidos.

Após a finalização da matriz, foi desenvolvido um questionário para a coleta de dados. O questionário foi estruturado utilizando o mesmo conceito da matriz, e as perguntas são de caráter qualitativo e quantitativo, com o objetivo de possibilitar a definição de médias e porcentagens necessárias para compor o campo de descritores, além de fornecer todas as informações para a aplicação da matriz na cidade de Orleans - SC.

O questionário foi aplicado a partir da leitura do PMGIRS (IPAT, 2013), consulta de dados contidos nos sites da Prefeitura Municipal, IBGE e do CIRSURES e, principalmente, com a realização de uma entrevista com o gestor responsável pela coleta de resíduos sólidos de Orleans. A entrevista foi agendada pelo Chefe de Gabinete do Prefeito de Orleans, Gabriel Sampaio Bianco, que participou juntamente com o responsável pela equipe de Serviços Urbanos, Rodrigo Vieira. O responsável pelo setor respondeu prontamente às questões referentes aos processos gerenciais, econômicos e socioculturais da coleta de RSU, e comentou a dificuldade de se obter informações quando ocorre troca de gestão administrativa na prefeitura, pois não há um banco de dados específico.

As informações referentes ao processo operacional, área de abrangência, população atendida, funcionamento do aterro sanitário e geração per capita, tanto da coleta convencional como da coleta seletiva, foram encontradas no site do CIRSURES. O consórcio possui uma página com elementos técnicos atualizados, relatórios de implantação e relatórios de funcionamento solicitados pelo órgão ambiental estadual FATMA.

Após o preenchimento do questionário, foi possível estabelecer os descritores dos indicadores através de cálculos para definir as médias adequadas e, então, realizar a aplicação da matriz no município de Orleans. Com a aplicação, determinou-se o nível de sustentabilidade (NS) utilizando o método de avaliação proposto por Santiago e Dias (2012), descrito no Quadro 3.

Quadro 3 - Nível de sustentabilidade

\begin{tabular}{|l|l|}
\hline Intervalo de sustentabilidade & Nível de sustentabilidade \\
\hline 0 & Insustentável \\
\hline $1,0<\mathrm{NS}<4,0$ & Baixa sustentabilidade \\
\hline $5,0<\mathrm{NS}<8,0$ & Média sustentabilidade \\
\hline $9>\mathrm{NS}>10$ & Alta sustentabilidade \\
\hline
\end{tabular}




\section{Fonte: Santiago e Dias, 2012.}

Seguindo os critérios propostos pelas autoras, o cálculo do nível de sustentabilidade da GRSU deve ser de acordo com a Equação 1.

$$
\mathrm{NS}=\frac{\Sigma \text { das notas obtidas na avaliaçẫo }}{\Sigma \text { dams notas obtidas na avaliaçẫopela }} x^{10^{-1}}(1)
$$

\section{RESULTADOS E DISCUSSÕES}

Com o processo de consulta aos mecanismos utilizados para a coleta de dados da gestão de RSU do município de Orleans, tornou-se possível a aplicação da matriz de indicadores. A determinação do NS do município em estudo foi acompanhada por uma avaliação qualitativa, em que foram descritos os aspectos positivos e aspectos negativos dos processos de gerenciamento integrado de resíduos sólidos. 
As Tabelas de 1 a 6 apresentam a estrutura final da matriz com as pontuações obtidas na avaliação do município e, respectivamente, a descrição dos aspectos.

Tabela 1 - Matriz de Indicadores de Sustentabilidade, dimensão Política/Institucional

\begin{tabular}{|c|c|c|c|c|c|}
\hline \multicolumn{3}{|r|}{ Indicador } & Descritor & Nota & Pontuação \\
\hline \multirow{24}{*}{ 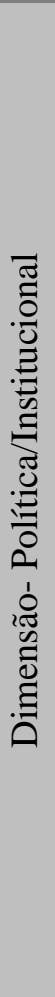 } & \multirow{3}{*}{1} & Possui um Plano Municipal de & Sim & 5 & \multirow[t]{3}{*}{ 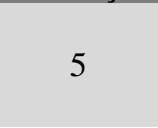 } \\
\hline & & Gestão Integrada de Resíduos & Em processo de conclusão & 3 & \\
\hline & & Sólidos & Não possui & 0 & \\
\hline & \multirow{3}{*}{2} & \multirow{3}{*}{$\begin{array}{l}\text { Participa de um consócio } \\
\text { intermunicipal }\end{array}$} & Sim, abrange coleta convencional e seletiva & 5 & \multirow{3}{*}{5} \\
\hline & & & Sim, abrange apenas coleta convencional & 3 & \\
\hline & & & Não participa & 1 & \\
\hline & \multirow{3}{*}{3} & \multirow{3}{*}{$\begin{array}{c}\text { Grau de estruturação da gestão de } \\
\text { RSU na administração pública } \\
\text { municipal }\end{array}$} & Setor específico para RSU estruturado & 5 & \multirow{3}{*}{2} \\
\hline & & & Setor específico não estruturado & 2 & \\
\hline & & & Inexistência & 0 & \\
\hline & \multirow{3}{*}{4} & Grau de capacitação dos & Todos possuem capacitação específica & 5 & \multirow{3}{*}{0} \\
\hline & & funcionários atuantes na gestão de & Parte dos funcionários & 3 & \\
\hline & & RSU & Nenhum & 0 & \\
\hline & \multirow{3}{*}{6} & \multirow{3}{*}{$\begin{array}{l}\text { Integralidade dos serviços de } \\
\text { saneamento básico }\end{array}$} & Água, esgoto, resíduos sólidos, drenagem & 5 & \multirow{3}{*}{5} \\
\hline & & & Dois a três serviços de saneamento & 3 & \\
\hline & & & Só abastecimento de água & 1 & \\
\hline & \multirow{3}{*}{7} & \multirow{3}{*}{$\begin{array}{l}\text { Grau de execução do Plano } \\
\text { Municipal de RSU vigente }\end{array}$} & Muitas metas atingidas & 5 & \multirow{3}{*}{3} \\
\hline & & & Poucas metas atingidas & 3 & \\
\hline & & & Nenhuma meta atingida & 1 & \\
\hline & \multirow{3}{*}{8} & \multirow{3}{*}{$\begin{array}{l}\text { Apresenta fiscalização dos serviços } \\
\text { de limpeza pública }\end{array}$} & Em todo o município & 5 & \multirow{3}{*}{2} \\
\hline & & & Apenas no centro da cidade sede & 2 & \\
\hline & & & Não Possui & 0 & \\
\hline & \multirow{3}{*}{9} & \multirow{3}{*}{$\begin{array}{l}\text { Existência de informações sobre a } \\
\text { gestão de RSU sistematizados e } \\
\text { disponibilizados para a população }\end{array}$} & Sistematizadas e divulgadas para a população & 5 & \multirow{3}{*}{1} \\
\hline & & & Sistematizadas, mas não acessíveis & 2 & \\
\hline & & & Não são sistematizadas & 1 & \\
\hline & \multicolumn{3}{|c|}{ SUBTOTAL MÁXIMO } & 45 & 23 \\
\hline
\end{tabular}

Fonte: Adaptada da pesquisa bibliográfica, 2017.

\section{Dimensão Política/Institucional}

Aspectos positivos: o município cumpriu o compromisso de estabelecer um Plano Intermunicipal de Gestão Integrada de Resíduos Sólidos, seguindo as diretrizes que constam na Lei 12.305/10. A participação em um consórcio intermunicipal pode ser vista como um ponto positivo, já que possibilita uma redução dos custos envolvidos, como previsto na PNRS. Outro fator importante é que há a integralidade dos serviços de saneamento básico.

Aspectos negativos: durante a pesquisa, a gestão apresentou falhas na estruturação da equipe, pois ainda não apresentava um organograma definido com o quadro funcional e de competência dos setores. Salienta-se o fato de o município não possuir as informações sobre os processos de gerenciamento adequadamente sistematizadas e disponibilizadas para a população. 
Mesmo não possuindo uma equipe estruturada e com a dificuldade de acesso a informações provenientes da gestão anterior, o atual responsável pelo setor de serviços urbanos revelou um forte interesse e empenho em estabelecer iniciativas que possam melhorar a qualidade da gestão de RSU no município. Ressalta-se que o registro de dados deve ser visto como prioridade, para facilitar as ações administrativas, promover o controle de gastos, a comunicação entre gestores e a divulgação de dados para a população. Nesse caso, podem ser utilizadas planilhas de controle para o registro mensal de gastos relacionados com a gestão de resíduos sólidos e outras informações importantes.

Tabela 2 - Matriz de Indicadores de Sustentabilidade, dimensão Operacional 1 - Coleta Convencional

\begin{tabular}{|c|c|c|c|c|c|}
\hline & & Indicador & Descritor & Nota & Pontuação \\
\hline \multirow{10}{*}{ 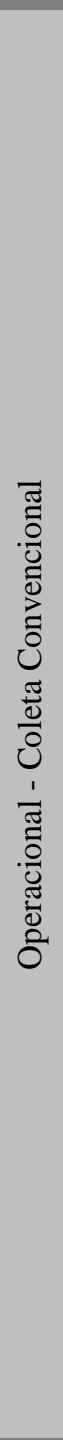 } & 10 & $\begin{array}{l}\text { Geração de RSU per capita } \\
\text { (kg/hab.ano) }\end{array}$ & 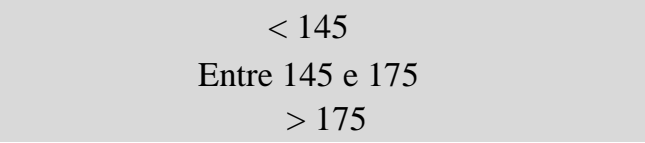 & $\begin{array}{l}5 \\
3 \\
1\end{array}$ & 5 \\
\hline & 11 & $\begin{array}{l}\text { Área de abrangência do serviço de } \\
\text { coleta }\end{array}$ & $\begin{array}{c}\text { Todo o município } \\
\text { Em toda a área urbana } \\
\text { Em parte da área urbana }\end{array}$ & $\begin{array}{l}5 \\
3 \\
1\end{array}$ & 5 \\
\hline & 12 & $\begin{array}{l}\text { Aterro sanitário/controlado } \\
\text { licenciado }\end{array}$ & $\begin{array}{l}\text { Sim } \\
\text { Em processo de licenciamento } \\
\text { Não licenciado ou Lixão }\end{array}$ & $\begin{array}{l}5 \\
3 \\
0\end{array}$ & 5 \\
\hline & 13 & $\begin{array}{l}\text { Existência de aterro para resíduos } \\
\text { inertes no município (construção e } \\
\text { demolição) }\end{array}$ & $\begin{array}{c}\text { Sim e com reaproveitamento } \\
\text { Sim e apenas para disposição } \\
\text { Não possui }\end{array}$ & $\begin{array}{l}5 \\
3 \\
0\end{array}$ & 0 \\
\hline & 14 & Existência de lixeiras públicas & $\begin{array}{c}\text { Em toda área urbana } \\
\text { Somente no centro da cidade } \\
\text { Não possui }\end{array}$ & $\begin{array}{l}5 \\
2 \\
0\end{array}$ & 2 \\
\hline & 15 & $\begin{array}{l}\text { Capacitação contínua de agentes que } \\
\text { atuam na área da limpeza pública }\end{array}$ & $\begin{array}{c}\text { Presença } \\
\text { Presença de forma esporádica } \\
\text { Ausência }\end{array}$ & $\begin{array}{l}5 \\
3 \\
0\end{array}$ & 3 \\
\hline & 16 & Utiliza mão de obra local & $\begin{array}{c}\text { Em todas as fases do gerenciamento de RSU } \\
\text { Administração e coleta } \\
\text { Apenas na coleta }\end{array}$ & $\begin{array}{l}5 \\
4 \\
1\end{array}$ & 4 \\
\hline & 17 & $\begin{array}{l}\text { Manutenção dos equipamentos } \\
\text { realizada localmente }\end{array}$ & $\begin{array}{c}\text { Em todas as fazes da gestão } \\
\text { Apenas transporte } \\
\text { Manutenção externa }\end{array}$ & $\begin{array}{l}5 \\
3 \\
1\end{array}$ & 3 \\
\hline & 18 & $\begin{array}{c}\text { Veículo coletor específico e } \\
\text { apropriado em termos de capacidade, } \\
\text { para a geração local }\end{array}$ & $\begin{array}{c}\text { Sim (apenas para essa função) } \\
\text { Sim (utilizado em outras funções) } \\
\text { Ausência }\end{array}$ & $\begin{array}{l}5 \\
3 \\
0\end{array}$ & 5 \\
\hline & 19 & $\begin{array}{l}\text { Existência de coleta seletiva no } \\
\text { município }\end{array}$ & $\begin{array}{l}\text { Sim } \\
\text { Em fase de implantação } \\
\text { Não existe }\end{array}$ & $\begin{array}{l}5 \\
3 \\
0\end{array}$ & 5 \\
\hline & & SUBTOTAL & MÁXIMO & 50 & 37 \\
\hline
\end{tabular}

Fonte: Adaptada da Pesquisa Bibliográfica, 2017. 


\section{Dimensão Operacional}

\section{Coleta Convencional}

Para o cálculo da geração per capita, utilizaram-se as informações do relatório de monitoramento realizado pela FATMA. Além disso, foi estabelecida uma média mensal da quantidade de resíduos sólidos depositados no aterro sanitário (no período de mai/16 à abr/17) e o número de habitantes estimado pelo IBGE. O resultado obtido foi de 159,48 kg/hab.ano.

Aspectos positivos: a geração per capita de resíduos sólidos no município não obteve um aumento significativo desde a implantação do PMGIRS. Ocorreu um aumento na área de abrangência da coleta convencional, o município adquiriu novos veículos coletores e, atualmente, o serviço de coleta abrange toda área municipal. Segundo o relatório (FATMA, 2017), o CIRSURES possui excelência estrutural e de funcionamento do aterro sanitário, onde são depositados os resíduos coletados em Orleans. A coleta seletiva foi implantada no município em 2015, um fato importante para a reutilização de materiais recicláveis e redução da disposição de resíduos no aterro sanitário.

Aspectos negativos: o Plano Municipal de Resíduos de Construção Civil ainda não foi implantado, o que pode gerar problemas administrativos e deposição desses resíduos. Outro ponto a ser ressaltado é a pouca quantidade de lixeiras públicas e formatos não funcionais, o que prejudica o armazenamento e, posteriormente, a coleta dos resíduos, interferindo na qualidade da limpeza urbana.

Com o cumprimento das metas estabelecidas pelo PMGIRS (IPAT, 2013), o serviço de coleta convencional se tornou mais qualificado, abrangendo, atualmente, todo o município, além de ser realizado com regularidade e compromisso. Salienta-se a importância da implantação do PMRCC e aconselha-se a instalação de aparelhos de GPS nos veículos de coleta para que se obtenha um valor referente à quantidade de resíduos coletados por quilometragem, intensificado o controle de geração.

Tabela 3 - Matriz de Indicadores de Sustentabilidade, dimensão Operacional 2 - Coleta Seletiva

\begin{tabular}{|c|c|c|c|c|c|}
\hline & & Indicador & Descritor & Nota & Pontuação \\
\hline$\frac{5}{5} \frac{0}{5}$ & 20 & $\begin{array}{l}\text { Massa per capita anual coletada } \\
\text { seletivamente ( } \mathrm{kg} / \mathrm{hab} . \mathrm{ano})\end{array}$ & $\begin{array}{c}>7 \mathrm{~kg} / \mathrm{hab} . \text { ano } \\
\text { Entre } 6 \text { a } 7 \mathrm{~kg} / \mathrm{hab} . \text { ano } \\
<6 \mathrm{~kg} / \mathrm{hab} . \text { ano }\end{array}$ & $\begin{array}{l}5 \\
4 \\
1\end{array}$ & 4 \\
\hline$\sum_{2}^{2}$ & 21 & $\begin{array}{l}\text { Percentual de pessoas atendidas pela coleta } \\
\text { seletiva }\end{array}$ & $\begin{array}{c}>80 \% \\
40 \% \text { a } 80 \%\end{array}$ & $\begin{array}{l}5 \\
2\end{array}$ & 1 \\
\hline
\end{tabular}




\begin{tabular}{|c|c|c|c|c|}
\hline & & $<40 \%$ & 1 & \\
\hline 22 & $\begin{array}{l}\text { Existência de pontos para entrega voluntária } \\
\text { (PEV'S) }\end{array}$ & $\begin{array}{c}\text { Atende mais de } 50 \% \text { da população } \\
\text { Atende menos de } 50 \% \text { da população } \\
\text { Não possui }\end{array}$ & $\begin{array}{l}5 \\
2 \\
0\end{array}$ & 0 \\
\hline 23 & $\begin{array}{l}\text { Taxa de recuperação de materiais recicláveis } \\
\text { em relação à quantidade total (QRSU+QRR) } \\
\text { coletada }\end{array}$ & $\begin{array}{l}>1,25 \% \\
1,12 \text { a } 1,20 \% \\
\text { Até } 1,00 \%\end{array}$ & $\begin{array}{l}5 \\
3 \\
2\end{array}$ & 2 \\
\hline 24 & $\begin{array}{c}\text { Participação de catadores nas ações de coleta } \\
\text { seletiva no município }\end{array}$ & $\begin{array}{c}\text { Organizados em cooperativas/associações } \\
\text { Isolada } \\
\text { Outra (grupos sem associação) }\end{array}$ & $\begin{array}{l}5 \\
3 \\
2\end{array}$ & 2 \\
\hline 25 & Inclusão de catadores avulsos & $\begin{array}{l}80 \text { a } 100 \% \\
50,1 \text { a } 79,9 \% \\
\quad<50 \%\end{array}$ & $\begin{array}{l}5 \\
3 \\
1\end{array}$ & 1 \\
\hline 26 & $\begin{array}{l}\text { Existência de cooperativas ou associações no } \\
\text { município ou consórcio }\end{array}$ & $\begin{array}{c}\text { No município e no consórcio intermunicipal } \\
\text { Em apenas um } \\
\text { Não existe }\end{array}$ & $\begin{array}{l}5 \\
3 \\
0\end{array}$ & 3 \\
\hline 27 & $\begin{array}{c}\text { Renda média mensal nas cooperativas (valor } \\
\text { médio pago aos catadores organizados em } \\
\text { cooperativas) }\end{array}$ & $\begin{array}{l}\text { Acima de } 1 \mathrm{SM} \\
\text { Entre } 0,5 \text { e } 1 \mathrm{SM} \\
\quad<0,5 \mathrm{SM}\end{array}$ & $\begin{array}{l}5 \\
3 \\
2\end{array}$ & 3 \\
\hline 28 & $\begin{array}{l}\text { Salubridade do local de trabalho dos catadores } \\
\text { (EPI, banheiros, refeitório, armazenamento } \\
\text { adequado do refugo e dos recicláveis, } \\
\text { cobertura, piso impermeabilizado) }\end{array}$ & $\begin{array}{l}\text { Contempla todos os itens } \\
\text { Somente EPI e banheiro } \\
\text { Ausência }\end{array}$ & $\begin{array}{l}5 \\
3 \\
0\end{array}$ & 5 \\
\hline & SUBTOTAL MÁ & XIMO & 45 & 21 \\
\hline
\end{tabular}

Fonte: Adaptada da pesquisa bibliográfica, 2017.

\section{Coleta seletiva}

O município implantou recentemente o programa de coleta seletiva, especificamente no ano de 2015. Segundo dados do relatório publicado pela FATMA, a coleta seletiva em Orleans correspondeu a 5,70 \% do total recolhido pelo programa de Coleta Seletiva do Cirsures. No total, foram recolhidos em Orleans, no ano de 2016, 35,04 toneladas de material reciclado. A população atendida pelo serviço de coleta de seletiva é de 5.504, 24,4\% da população total. A geração per capita foi calculada utilizando dados do ano de 2016, resultando em $6,36 \mathrm{~kg} / \mathrm{hab}$. ano.

Aspectos positivos: a implantação de um Programa Intermunicipal de Coleta Seletiva promove avanços ambientais importantes e intensifica as ações de reutilização de materiais recicláveis, gerando retornos econômicos e inclusão social. A Cooperamérica, cooperativa responsável pela triagem dos materiais coletados, corresponde às exigências de salubridade do local onde são realizados os processos de triagem e armazenamento de recicláveis, ponto a ser salientado. 
Aspectos negativos: o serviço de coleta seletiva abrange uma pequena porção da população. Dessa forma, poderia ser considerada futuramente a ampliação do programa, para incentivar separação na fonte para coleta em rotas de diferenciadas e posterior reciclagem de resíduos domésticos, diminuindo os custos com a coleta convencional. Outro ponto negativo que deve ser salientado é a não existência de programas de inclusão de catadores.

Deve-se ressaltar que o programa de coleta seletiva foi implantado recentemente no município e muitas medidas devem ser consideradas para a ampliação do serviço.

Tabela 4 - Matriz de Indicadores de Sustentabilidade, dimensão Econômica

\begin{tabular}{|c|c|c|c|c|c|}
\hline \multirow{5}{*}{ 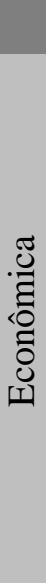 } & \multicolumn{2}{|r|}{ Indicador } & Descritor & Nota & Pontuação \\
\hline & 29 & $\begin{array}{l}\text { Origem dos recursos para o } \\
\text { gerenciamento de resíduos sólidos }\end{array}$ & $\begin{array}{c}\text { Taxa específica para o serviço de limpeza pública } \\
\text { Cobrança de taxa junto com o IPTU } \\
\text { Não existência de taxa }\end{array}$ & $\begin{array}{l}5 \\
4 \\
0\end{array}$ & 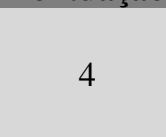 \\
\hline & 30 & $\begin{array}{c}\text { Comparação do custo da coleta regular } \\
\text { em relação à taxa de cobrança } \\
\text { arrecadada }\end{array}$ & $\begin{array}{l}\text { Menor que a taxa } \\
\text { Igual à taxa } \\
\text { Maior que a taxa }\end{array}$ & $\begin{array}{l}5 \\
2 \\
0\end{array}$ & 0 \\
\hline & 31 & $\begin{array}{c}\text { Custo da coleta seletiva em relação } \\
\text { à coleta regular e disposição final } \\
\text { adequada - \% }\end{array}$ & $\begin{array}{l}<50 \% \\
50,1 \text { a } 199,9 \% \\
>200 \%\end{array}$ & $\begin{array}{l}5 \\
3 \\
1\end{array}$ & 5 \\
\hline & 32 & $\begin{array}{l}\text { Aplicação dos recursos provenientes } \\
\text { da coleta seletiva }\end{array}$ & $\begin{array}{c}\text { Na própria manutenção da coleta seletiva } \\
\text { Atividades socioculturais e assistenciais } \\
\text { Sem aplicação }\end{array}$ & $\begin{array}{l}5 \\
3 \\
0\end{array}$ & 0 \\
\hline & & SUBTOTA & , MÁXIMO & 20 & \\
\hline
\end{tabular}

Fonte: Adaptada da pesquisa bibliográfica, 2017.

\section{Dimensão econômica}

A Lei Complementar 1923/2005, art. 395 do município de Orleans, institui a arrecadação da Taxa de Coleta e Remoção de Resíduos Sólidos, que está incluída no IPTU. Segundo a informação disponibilizada pela Prefeitura Municipal de Orleans, a arrecadação no ano de 2016 foi de R $\$$ 511.706,74. O cálculo do custo do programa de coleta convencional não pode ser definido pela falta de dados importantes, mas, comparando os custos com funcionários e o custo por tonelada de resíduo depositado no aterro sanitário com a taxa arrecadada, conclui-se que o custo final da gestão de RSU é mais elevado do que a última arrecadação. O custo da coleta seletiva é fixo, pois todos os processos são de responsabilidade do CIRSURES, e o valor do contrato em vigor divulgado pelo consórcio é de $\mathrm{R} \$ 26.390,20$.

Aspectos positivos: deve ser ressaltada a importância de o município possuir um sistema de arrecadação instituído por lei e disponibilizar para a população os valores arrecadados. 
Aspectos negativos: os custos dos processos do serviço de coleta convencional não são sistematizados adequadamente. Além disso, não há registro da quilometragem realizada pelos veículos de coleta, impossibilitando o cálculo do valor gasto com óleo diesel. Não há arrecadação proveniente dos materiais reciclados.

A avaliação dessa dimensão salienta a importância de se estabelecer um banco de dados, para que se obtenha o controle dos custos que englobam o gerenciamento municipal de RSU.

Tabela 5 - Matriz de Indicadores de Sustentabilidade, dimensão Ambiental/Ecológica

\begin{tabular}{|c|c|c|c|c|c|}
\hline \multicolumn{3}{|r|}{ Indicador } & Descritor & Nota & Pontuação \\
\hline \multirow{21}{*}{ 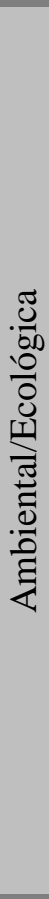 } & \multirow{3}{*}{33} & Número de pontos de resíduos & Nenhum & 5 & \multirow{3}{*}{ - } \\
\hline & & clandestinos/extensão total das vias em & 0,1 a 0,4 & 2 & \\
\hline & & $\mathrm{km}$ & $>0,4$ & 0 & \\
\hline & \multirow{3}{*}{34} & Grau de implementação das medidas & L.A realizado e medidas implantadas & 5 & \multirow{3}{*}{5} \\
\hline & & previstas no licenciamento das & L.A realizado sem implantação & 3 & \\
\hline & & atividades relacionadas aos RSU & Inexistência & 0 & \\
\hline & \multirow{3}{*}{35} & \multirow{3}{*}{$\begin{array}{c}\text { Grau de recuperação dos passivos } \\
\text { ambientais }\end{array}$} & Todas as áreas degradadas recuperadas & 5 & \multirow{3}{*}{5} \\
\hline & & & Mapeadas mas não recuperadas & 2 & \\
\hline & & & Não mapeadas ou sem recuperação & 0 & \\
\hline & \multirow{3}{*}{36} & \multirow{3}{*}{$\begin{array}{l}\text { Grau de recuperação dos RSU que } \\
\text { estão sob responsabilidade do Poder } \\
\text { Público }\end{array}$} & Alta recuperação dos RSU & 5 & \multirow{3}{*}{3} \\
\hline & & & Baixa recuperação dos RSU & 3 & \\
\hline & & & Muito baixa ou inexistente & 1 & \\
\hline & \multirow{3}{*}{37} & \multirow{3}{*}{ Recuperação de resíduo orgânico } & Acima de $30 \%$ & 5 & \multirow{3}{*}{2} \\
\hline & & & Entre 5,1 e $30 \%$ & 3 & \\
\hline & & & Até $5 \%$ & 2 & \\
\hline & \multirow{3}{*}{38} & \multirow{3}{*}{ Eficiência da coleta convencional } & 91 a $100 \%$ & 5 & \multirow{3}{*}{5} \\
\hline & & & 31 a $90 \%$ & 3 & \\
\hline & & & $<30 \%$ & 2 & \\
\hline & \multirow{3}{*}{39} & \multirow{3}{*}{ Eficiência da coleta seletiva } & 91 a $100 \%$ & 5 & \multirow{3}{*}{5} \\
\hline & & & 31 a $90 \%$ & 3 & \\
\hline & & & $<30 \%$ & 2 & \\
\hline & \multicolumn{3}{|c|}{ SUBTOTAL MÁXIMO } & 35 & 27 \\
\hline
\end{tabular}

Fonte: Adaptada da pesquisa bibliográfica, 2017.

\section{Dimensão ambiental/ecológica}

Aspectos positivos: tanto a coleta convencional quanto a coleta seletiva possuem boa eficiência, pois todas as coletas programadas são executadas. As medidas previstas no licenciamento ambiental estão integralmente implementadas. O estudo realizado para a definição do diagnóstico para implantação do PMGIRS (IPAT, 2013) identificou a área do antigo lixão de Orleans. O projeto de recuperação foi implantado em 2003. Atualmente, a área encontra-se devidamente recuperada. 
Aspectos negativos: existem pontos de resíduos clandestinos, geralmente denunciados pela própria população.

Os impactos negativos gerados pela existência de pontos de resíduos clandestinos devem ser prevenidos, através de mecanismos de mapeamento e fiscalização. Deve-se salientar que esse tipo de destinação é proibido conforme o conteúdo da Lei 12.305/10.

Tabela 6 - Matriz de Indicadores de Sustentabilidade, dimensão Social/Cultural

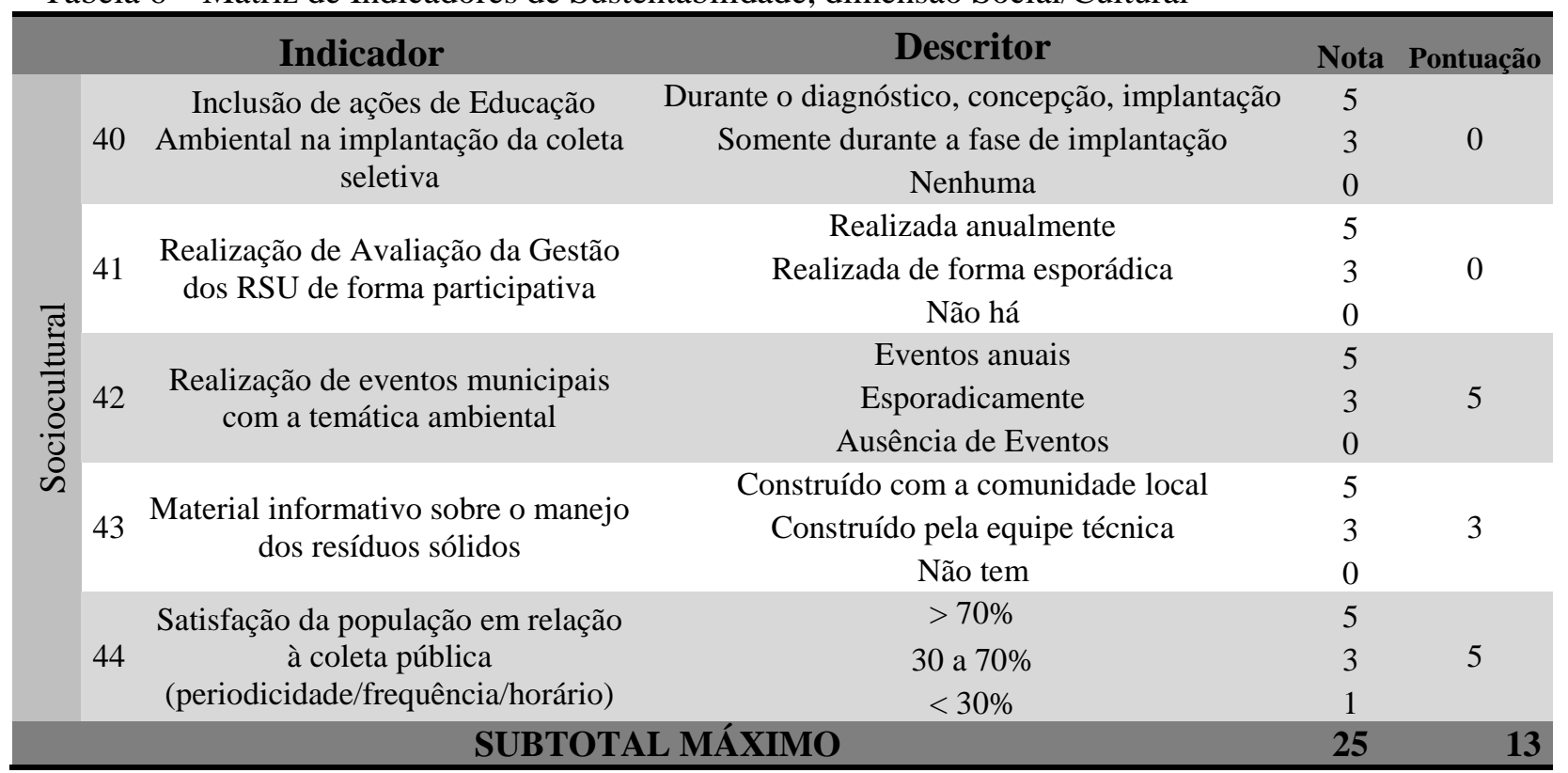

Fonte: Adaptada da pesquisa bibliográfica, 2017.

\section{Social/cultural}

Aspectos positivos: os eventos ambientais são realizados anualmente no município de Orleans, promovendo a divulgação de informações referentes à sustentabilidade do meio ambiente.

Aspectos negativos: a avaliação aponta que os aspectos negativos da dimensão sociocultural estão relacionados com a dificuldade de realizar a gestão de RSU de forma participativa, pois a maior parte da população não demonstra interesse pelas questões que envolvem o serviço de coleta de resíduos.

Algumas ações podem ser promovidas para que ocorra uma comunicação efetiva com a população: a divulgação dos programas de coleta, desenvolvimento de projetos de educação ambiental acessíveis, programas de incentivo à reciclagem e divulgação de informações, entre outras. 
O envolvimento da população como corresponsável do berço ao berço dos resíduos sólidos se constrói mediante práticas e estratégias continuadas de educação ambiental para repensar hábitos de consumo e descarte, orientar no sentido do consumo sustentável e efetivamente separar na origem em categorias que possibilitem rotas tecnológicas que valorizem os materiais orgânicos em processo de compostagem, os materiais recicláveis para a coleta seletiva com inclusão social produtiva de catadores e catadoras e o destino ambientalmente adequado apenas de rejeitos para o aterro sanitário.

\section{Determinação do nível de sustentabilidade}

A pontuação alcançada após a avaliação da gestão de RSU no município de Orleans está representada na Tabela 7.

Tabela 7 - Pontuação da matriz

\begin{tabular}{l|c|c}
\hline \multicolumn{1}{|c|}{ Dimensão } & $\begin{array}{c}\text { Pontuação máxima } \\
\text { por dimensão }\end{array}$ & $\begin{array}{c}\text { Pontuação alcançada } \\
\text { por dimensão }\end{array}$ \\
\hline Política/Institucional & 45 & 23 \\
\hline Operacional 1 & 50 & 37 \\
Operacional 2 & 45 & 21 \\
\hline Econômica & 20 & 9 \\
\hline Ambiental/Ecológica & 35 & 27 \\
\hline Sociocultural & 25 & 13 \\
\hline Pontuação Total & $\mathbf{2 2 0}$ & $\mathbf{1 3 0}$ \\
\hline Resultado Avaliação & \multicolumn{2}{|c|}{$\mathbf{5 , 9}$} \\
\hline Nível de Sustentabilidade & \multicolumn{2}{|c}{ Média Sustentabilidade } \\
\hline Fon
\end{tabular}

Fonte: Dados da pesquisa, 2017.

Com base no resultado do cálculo utilizando a Equação 1, obteve-se um NS de 5,9 para o município em estudo. Esse resultado está inserido no intervalo de Média Sustentabilidade.

\section{CONCLUSÃO}

Em conformidade com os resultados obtidos, constatou-se a eficácia dos métodos aplicados sobre indicadores de sustentabilidade em gestão e gerenciamento de resíduos 
sólidos. A revisão da literatura sobre a aplicação de indicadores de sustentabilidade possibilitou a análise dos padrões determinados pelos autores Polaz e Teixeira (2009); Santiago e Dias (2012); Fechine e Moraes (2014) e permitiu que fosse estabelecido um estudo aplicado prévio considerando as particularidades do município de Orleans - SC.

A composição final da matriz considera as varáveis políticas, operacionais, econômicas, ambientais e socioculturais adaptadas às especificidades da gestão e gerenciamento de resíduos sólidos urbanos. A avaliação dos aspectos pontua os problemas e auxilia na definição das prioridades para a otimização dos processos de gerenciamento.

Essa ferramenta se mostrou importante para a avaliação da gestão de resíduos, podendo auxiliar no monitoramento e planejamento. Caso seja utilizada por gestores públicos periodicamente como instrumento de análise, pode contribuir para tornar as características da gestão mais transparentes à sociedade em geral e superar os obstáculos que impossibilitam o armazenamento e a disponibilização de dados referentes à gestão de resíduos sólidos urbanos.

\section{REFERÊNCIAS}

BELLINGIERI, P.H. Sistema de informações sobre resíduos como instrumento de gestão. In: JARDIM, A.; YOSHIDA, C.; MACHADO FILHO, J. V. (Orgs.). Política nacional, gestão e gerenciamento de resíduos sólidos. Barueri, SP: Manole, 2012. p. 245-281. (Coleção Ambiental 1).

BESEN, Gina Rizpah; RIBEIRO, Helena. Indicadores de sustentabilidade para programas municipais de coleta seletiva - métodos e técnicas de avaliação. Curso de Especialização em Planejamento do Desenvolvimento e Integração Regional na Universidade Federal no Pará. Belém: UFPA, 2008. Disponível em: 〈http://www.ufpa.br/epdir/images/docs/paper53.pdf>. Acesso em: 20 ago. 2017.

BRASIL. DECRETO N. 7.404, DE 23 DE DEZEMBRO DE 2010. Regulamenta a Lei no 12.305, de 2 de agosto de 2010, que institui a Política Nacional de Resíduos Sólidos, cria o Comitê Interministerial da Política Nacional de Resíduos Sólidos e o Comitê Orientador para a Implantação dos Sistemas de Logística Reversa, e dá outras providências. Diário Oficial da União, 23 dez. 2010. Disponível em: <http://www.planalto.gov.br/ccivil_03/_Ato20072010/2010/Decreto/D7404.htm>. Acesso em: 15 ago. 2011.

BRASIL. Lei n.12.305, de 2 de agosto de 2010: Institui a Política Nacional de Resíduos Sólidos; altera a Lei no 9.605, de 12 de fevereiro de 1998; e dá outras providências. Diário Oficial da União, 3 ago. 2010. Disponível em: <http://www.mma.gov.br/port/conama/legiabre.cfm?codlegi=636>. Acesso em: 7 ago. 2011. CRESWELL, J. W. 1: Seleção de um projeto Projeto de Pesquisa. In: CRESWELL, J. W. Projeto de pesquisa: Métodos qualitativo, quantitativo e misto. 3. ed. Porto Alegre: Artmed, 2010. 2 p. 24. Disponível em: <\&lt;http://downloads.artmed.com.br/public/C/CRESWELL_John_W/Projeto_Pesquisa_3Ed/ Liberado/Cap_01.pdf\&gt;>. Acesso em: 16 jul. 2017. 
DANTAS, Katia Monte Chiari. Proposição e avaliação de sistemas de gestão ambiental integrada de resíduos sólidos através de indicadores em municípios do estado do Rio de Janeiro. 2008. 401 f. Tese (Doutorado Engenharia Civil) - Universidade Federal do Rio de Janeiro, Rio de Janeiro, 2008.

FECHINE, Roberta; MORAES, Luiz Roberto. Indicadores de sustentabilidade como instrumentos para avaliação de programas de coleta seletiva de resíduos sólidos urbanos e sua aplicação na cidade de Salvador - BA. Revista Eletrônica de Gestão e Tecnologia Ambientais (GESTA), v. 2, n. 1, p. 87-104, 2014.

MILANEZ, Bruno. Resíduos sólidos e sustentabilidade: princípios, indicadores e instrumentos de ação. 2002. 207 f. Dissertação (Mestrado em Engenharia Urbana) Universidade Federal de São Carlos, São Paulo, 2002.

ORLEANS. Lei Complementar n. 1923, de 13 de dezembro de 2005: Dispõe sobre sistema tributário municipal de Orleans e as normas gerais de direito tributário aplicável ao município. Disponível em: <https://leismunicipais.com.br/a/sc/o/orleans/leicomplementar/2005/192/1923/lei-complementar-n-1923-2005-dispoe-sobre-sistematributario-municipal-de-orleans-e-as-normas-gerais-de-direito-tributario-aplicavel-aomunicipio>. Acesso em:20 ago. 2017.

PHILIPPI JR. Arlindo et al. Gestão Integrada de Resíduos sólidos In.: JARDIM, A.;YOSHIDA, C.; MACHADO FILHO, J. V. (Orgs.). Política Nacional, Gestão e Gerenciamento de Resíduos Sólidos. Barueri, SP: Manole, 2012. p. 229-244. (Coleção Ambiental 1).

POLAZ, Carla Marcolino; TEIXEIRA, Bernardo Arantes. Indicadores de sustentabilidade para a gestão municipal de resíduos sólidos urbanos: um estudo para São Carlos (SP). Engenharia Sanitária Ambiental, v. 14, n. 3, p. 411-420, jun. 2009.

Relatório anual de operação do Aterro Sanitário - FATMA. Disponível em: <http://www.cirsures.sc.gov.br/biblioteca/relatorios/download/pdf/7c7d128dded94b86e98a34 ca21411c49/relatorio-fatma-2016-2017_2017-06-19.pdf>. Acesso: 20 ago. 2017.

RELATÓRIO Coleta Seletiva 2016 - FATMA. Disponível em: <http://www.cirsures.sc.gov.br/institucional/documentos/download/pdf/a9e7307cb46e8c26e8 4e028b58d87589/relatorio-coleta-seletiva-2016_2017-05-18.pdf>. Acesso: 15 ago. 2017.

SANTIAGO, Leila Santos; DIAS, Sandra Furiam. Matriz de indicadores de sustentabilidade para a gestão de resíduos sólidos urbanos. Engenharia Sanitária Ambiental, v. 17, n. 2, p. 203-212, jun. 2012. 